\title{
IS THE LEVEL OF CYCLIC AMP IN THE PYLORIC CAECA OF THE STARFISH ASTERIAS RUBENS RELATED TO THE REPRODUCTIVE CYCLE?
}

\author{
P. A. Voogt and J. W. A. VAn RheEnen \\ Laboratory of Chemical Animal Physiology, State University of Utrecht, Utrecht, The Netherlands \\ (Tel: 030-532578)
}

(Received 19 December 1983)

\begin{abstract}
Cyclic AMP levels were significantly higher $(P=0.01)$ in female than in male animals. The average difference found was $0.50 \mathrm{pmole} / \mathrm{mg}$ dry weight.

2. Cyclic AMP levels were negatively correlated to the pyloric caeca-index. In females this correlation was $-0.54(P<0.05)$.

3. Cyclic AMP levels in the females paralleled the stages of the reproductive cycle. The level was significantly lower in stage II than in stage I and stage IV by 1.98 and $2.33 \mathrm{pmole} / \mathrm{mg}$ dry weight, respectively. The physiological significance of this pattern is discussed.

4. Cyclic AMP levels in male animals suggest a subdivision of the reproductive cycle into three stages. During the spermatogenic stage, cyclic AMP levels are significantly lower than in the other stages. The average differences found were 1.01 and $1.52 \mathrm{pmole} / \mathrm{mg}$ dry weight.
\end{abstract}

\section{INTRODUCTION}

It is generally accepted that the materials required for gametogenesis in sea stars originate from the pyloric caeca. This can be concluded from the inverse relationship between the gonad-index and the pyloric caeca-index during the year (e.g. Anderson 1953; Jangoux and Van Impe, 1977), but also from the similarity in the biochemical composition of the materials in the pyloric caeca and the gonads (Oudejans et al., 1979). This means that the pyloric caeca are indirectly concerned with the process of gametogenesis which implies that the intensity of the mobilization of reserve substances will reflect the varying needs of gametogenesis.

Among the reserves in Asterias rubens, proteins and lipids are the most important ones, whereas glycogen amounts in the pyloric caeca are small (Oudejans et al., 1979; Van der Plas and Voogt, 1982). In vertebrates mobilization of glycogen and triacylglycerols takes place by phosphorylation of the enzymes glycogen phosphorylase and triacylglycerol lipase, respectively, by a c-AMP dependent protein kinase (Meisner and Carter, 1977). In the pyloric caeca of Asterias rubens a lipase was found of which the activity was strongly dependent on the c-AMP level (Oudejans et al., 1983). This may indicate that the mobilization of reserves in starfish proceeds in a way similar to that in vertebrates.

Therefore it was interesting to know whether the level of c-AMP in the pyloric caeca varies during the year and whether these changes are correlated to gonadal growth.

Little is known about the c-AMP level in postmetamorphic sea stars. As far as we know, it is limited to a recent report on Luidia clathrata (Diehl, 1983) in which c-AMP levels are given for several organs of a total of five animals at one time of the year.
This paper presents the cyclic AMP levels in the pyloric caeca of Asterias rubens which had been collected at different times during a period of over a year.

\section{MATERIALS AND METHODS}

\section{Animals}

Adult Asterias rubens were collected from the population in the Wadden Sea (The Netherlands) at different times during the period November 1978-February 1980. They were kept in the laboratory in recirculating sea water at $12^{\circ} \mathrm{C}$ and natural day-length for 2 days during which no food was offered to have the alimentary canal freed from food residues. After dissection the animals were sexed and the gonad-index and the pyloric caeca-index were determined.

These organ indices were defined as:

$$
\frac{\text { fresh weight of the organ }}{\text { fresh weight of the total animal }} \times 100 \% \text {. }
$$

At each sampling date 4-6 animals of each sex were processed.

\section{Estimation of cyclic AMP level}

Immediately after the excision of the pyloric caeca small pieces of tissue were immersed in liquid nitrogen and then lyophilized. From each animal at least $100 \mathrm{mg}$ of this dried material was homogenized in $20 \mathrm{vol}$ of ice-cold $4 \%$ trichloroacetic acid with a Potter-Elvehjem homogenizer with a Teflon pestle. The homogenate was centrifuged at $40,000 \mathrm{~g}$ for $15 \mathrm{~min}$. The supernatant was neutralized with solid calcium carbonate and then washed three times with 5 vol of diethyl ether saturated with water. The water phase was lyophilized and the residue dissolved in Tris-buffer $(50 \mathrm{mM}$, pH 7.5) containing $4 \mathrm{mM}$ EDTA $(5 \mathrm{ml} / 100 \mathrm{mg}$ dry tissue). Cyclic AMP in this solution was measured in duplicate by competitive binding assay using kits obtained from the Radiochemical Centre, Amersham (UK). Radioactivities were measured in a Packard liquid scintillation spectrometer (Model 2420) using Emulsifier 299 (Packard) as the scintillation medium. 


\section{RESULTS AND DISCUSSION}

The gonad-index, the pyloric caeca-index, and the level of c-AMP in the pyloric caeca were determined for each animal. The respective data obtained for the animals of the same sex and sampling date were averaged. The results are given in Table 1 .

This table shows that cyclic AMP levels are not constant during the year, and from the standard deviations it can be derived that there are great differences in the c-AMP level among the individual animals.

Obviously the changes in the c-AMP levels follow the same pattern in both sexes. Moreover, according to the sign-test, the levels in female animals are significantly higher than those in male animals $(P=0.01)$. It is probable that this sex-dependent difference is due to processes related to reproduction, and should be ascribed to the higher demands of reproduction in females than in males, which is normally reflected in a higher gonad-index in female animals. Also in this study gonad-indices of female animals are higher than those of male animals. If this interpretation is correct, this is an indication that c-AMP levels reflect the demands of gametogenesis.

Diehl (1983) did not find different cyclic AMP levels in the pyloric caeca of female and male specimens of the starfish Luidia clathrata, but his observations comprised only two animals of each sex and were made only at one time of the year. The level he found amounted to $0.309 \pm 0.172$ pmoles $/ \mathrm{mg}$ wet tissue. The mean levels found in Asterias rubens are about 3 pmoles/mg dry weight; assuming a content of dry material in the pyloric caeca of about $30 \%$ (Van der Plas and Voogt 1982), this corresponds to a level of about $1 \mathrm{pmole} / \mathrm{mg}$ wet tissue, which is about three times that of Luidia clathrata, but is in the same order as that in mammalian liver (Gilman, 1972).

The course of the c-AMP levels within one sex is not easily interpretable, which is mainly due to the extremely high c-AMP levels recorded in January. In female animals this high level of c-AMP coincides with a decrease of the gonad-index, which is expected to increase in this time. This decrease is even continued in February and occurs in both sexes. It is most likely that this phenomenon is caused by the abnormal water temperatures during that period (Table 1).

Also in some Asterias vulgaris populations a winter plateau in the gonad-index curves has been observed, which has been interpreted as a response to low winter temperatures (Boolootian, 1966; Lowe, 1978). Hancock (1955) reported that Asterias rubens in British waters stops feeding entirely at temperatures below $3^{\circ} \mathrm{C}$. If this also holds good for the Wadden Sea population, an eventual continuation of gametogenesis (and all other energy demands) would completely bear on the reserves in the pyloric caeca. However, histological examination of the ovaries from animals collected at that time, revealed the presence of numerous degenerating oocytes and phagocytizing cells. The resorption of large oocytes at low winter temperatures has also been observed in Asterias vulgaris (Lowe, 1978). Harrold and Pearse (1980) concluded from their experiments with fed and starved sea stars, that in Pisaster giganteus somatic maintenance comes before reproduction. Therefore it

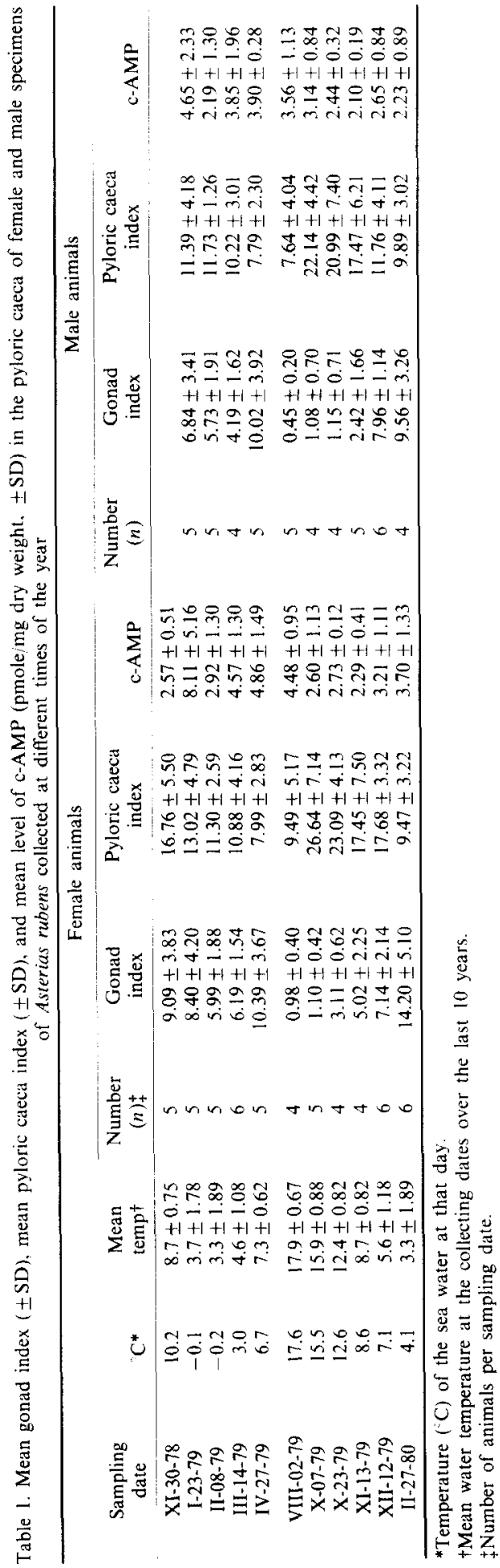


Table 2. Correlations between the gonad index, pyloric caeca index and c-AMP levels in the pyloric caeca of female and male specimens of Asterias rubens in two periods of increasing gonad index

\begin{tabular}{|c|c|c|c|c|c|c|}
\hline & \multicolumn{2}{|c|}{$\begin{array}{c}\text { Period } \\
\text { I }\end{array}$} & \multicolumn{2}{|c|}{$\begin{array}{l}\text { Period } \\
\text { II }\end{array}$} & \multicolumn{2}{|c|}{$\begin{array}{c}\text { Period } \\
\text { I + II }\end{array}$} \\
\hline & Q & $d$ & q & $\delta$ & 早 & 3 \\
\hline$r$ (pyloric caeca index, c-AMP level) & $-0.42 \dagger$ & -0.38 & $-0.49^{*}$ & -0.01 & $-0.54^{*}$ & $-0.27 \dagger$ \\
\hline$r$ (c-AMP level, gonad index) & +0.20 & +0.29 & +0.20 & -0.18 & +0.20 & +0.14 \\
\hline$r$ (pyloric caeca index, gonad index) & $-0.45^{*}$ & -0.32 & $-0.65^{*}$ & $-0.64^{*}$ & $-0.57^{*}$ & $-0.60^{*}$ \\
\hline Number of animals in period & 16 & 14 & 25 & 23 & 41 & 37 \\
\hline Number of sampling dates in period & 3 & 3 & 5 & 5 & 8 & 8 \\
\hline
\end{tabular}

is understandable that under these extreme climatological conditions gametogenesis is reversed and the gonad-index decreases. Initially there may have been a strong demand for nutrients on the pyloric caeca, resulting in abnormally high c-AMP levels. Later on gametogenesis stopped and the materials needed for energy generation are mainly obtained from the gonads. This would explain the lower c-AMP levels in the pyloric caeca in February 1979. Therefore the data obtained in January and February 1979 may be non-representative, and it seems better to leave them out.

In the periods February-April, 1979 (I) and October, 1979-February 1980 (II) the gonad-index increases and the correlations between this index, the pyloric caeca-index and the c-AMP levels were determined. These data are summarized in Table 2.

This table shows that in period II, in the total period (I + II), and for female specimens also in period $I$, there is a significant negative correlation between the gonad-index and the pyloric caeca-index, which on the ground of earlier findings could be expected. In female animals there is a significant negative correlation between the pyloric caeca-index and c-AMP level in the pyloric caeca in period II and in the whole period. In male animals this negative correlation is not significant. The correlation between the gonad-index and the c-AMP level in the pyloric caeca is positive, as was expected, but is not significant in any of the sexes.

The latter result was not unexpected, for it is very likely that the expectation of a rectilinear relationship between the gonad-index and the c-AMP level in the pyloric caeca-as the reflection of the supposed cooperation of gonad and pyloric caeca in reproductionis not justified.

Schoenmakers et al. (1983) studied the reproductive cycle of female sea stars and subdivided it into four stages: stage I (resting stage) lasting from middle of May-middle of September; stage II (the early growth stage) from the middle of September-end of November; stage III (stage of late growth and partial maturation) from the end of November-the middle of February: stage IV (maturation stage) from the middle of February-middle of May. When the data on c-AMP levels in female animals are arranged according to this division into stages, the picture shown in Table 3 is obtained. It strongly suggests, that c-AMP levels do not change gradually but stepwise.

By pooling the data of animals being in the same stage of the reproductive cycle, Table 4 is obtained. Analysis of variance of these data and subsequent testing of differences between stages (by means of a modified $t$-test, a multiple comparison technique based on the Bonferroni inequality (Miller, 1980), revealed that c-AMP levels in stage II are significantly lower than in stage $I(P=0.02)$ and stage IV $(P<0.001)$, and that the c-AMP level in stage III is significantly lower than in stage IV $(P=0.03)$. Cyclic AMP levels in stage I differ only from those in stage II, while those in stage IV are significantly higher than those in stages II and III.

The data on male sea stars show a simpler picture. Unfortunately, a clear subdivision of the reproductive cycle into stages for male animals is not available. The data on c-AMP levels allow for an arrangement into three groups. The first group comprises the sampling dates August 2 and October 7 , 1979; the second group the data from 23 October, November, December, 1979 and February 1980; the third group the data from March and April, 1979. The first group may be analogous to the resting stage of the female animals and may be the aspermatogenic phase. It is well known that the growth of the testes

Table 3. Cyclic AMP levels (pmole/mg dry weight, $\pm S D$ ) in pyloric caeca of female sea stars from different stages of the reproductive cycle

\begin{tabular}{lccc}
\hline Stage & $\begin{array}{c}\text { Sampling } \\
\text { date }\end{array}$ & $\begin{array}{c}\text { Number } \\
\text { of } \\
\text { animals }\end{array}$ & $\begin{array}{c}\text { Level } \\
\text { of } \\
\text { c-AMP }\end{array}$ \\
\hline I & VIII-02-79 & 4 & $4.48 \pm 0.95$ \\
II & X-07-79 & 5 & $2.60 \pm 1.13$ \\
& X-23-79 & 4 & $2.73 \pm 0.12$ \\
& XI-13-79 & 4 & $2.29 \pm 0.41$ \\
& XI-30-78 & 5 & $2.57 \pm 0.51$ \\
III & XII-12-79 & 6 & $3.21 \pm 1.11$ \\
& II-27-80 & 6 & $3.70 \pm 1.33$ \\
IV & III-14-79 & 6 & $4.57 \pm 1.30$ \\
& IV-27-79 & 5 & $4.86 \pm 1.49$ \\
\hline
\end{tabular}

Table 4. Cyclic AMP levels (pmole/mg dry weight, $\pm S D$ ) in the pyloric caeca of female sea stars which are in the same stage of the reproductive cycle

\begin{tabular}{ccc}
\hline Stage & $\begin{array}{c}\text { Number } \\
\text { of } \\
\text { animals }\end{array}$ & $\begin{array}{c}\text { Mean level } \\
\text { of } \\
\text { c-AMP }\end{array}$ \\
\hline I & 4 & $4.48 \pm 0.95$ \\
II & 18 & $2.50 \pm 0.75$ \\
III & 12 & $3.37 \pm 1.35$ \\
IV & 11 & $4.83 \pm 1.76$ \\
\hline
\end{tabular}


Table 5. Cyclic AMP levels (pmole/mg dry weight. $\pm \mathrm{SD}$ ) in the pyloric caeca of male sea stars which are supposed to be in a particular stage of the reproductive cycle

\begin{tabular}{|c|c|c|}
\hline Stage & $\begin{array}{c}\text { Number } \\
\text { of } \\
\text { animals }\end{array}$ & $\begin{array}{c}\text { Mean level } \\
\text { of } \\
\text { c-AMP }\end{array}$ \\
\hline Aspermatogenic stage & 9 & $3.37 \pm 0.98$ \\
\hline Spermatogenic stage & 19 & $2.36 \pm 0.64$ \\
\hline $\begin{array}{l}\text { Post-spermatogenic stage } \\
\text { (mature testes) }\end{array}$ & 9 & $3.88 \pm 0.62$ \\
\hline
\end{tabular}

generally starts half a month or a month later than that of the ovaries and this may explain why the male animals collected on 7 October were physiologically still in the resting stage whereas the female animals of that date had already entered stage II. The second group might comprise those animals in which spermatogenesis is going on, while in the animals of the third group spermatogenesis has already stopped and spermatozoa are ready to be shed.

The c-AMP levels of animals belonging to the groups assumed to be in the same stage have been averaged and are shown in Table 5 . These data were statistically tested in the same way as above. This revealed that the c-AMP level in the "spermatogenic" stage is significantly lower than that in the "aspermatogenic" phase $(0.003<P<0.03)$ and in the "post-spermatogenic" stage $(P<0.003)$.

Since the subdivision of the reproductive cycle of the male animals into stages is only tentative and is not based on a thorough histological examination it is not useful to speculate further on the physiological significance of the c-AMP levels in the pyloric caeca.

In female animals stage $I$ is characterized among others by the developing (or filling) of the haemal system in the ovaries, which in the foregoing stage (stage IV) is hardly visible and devoid of its normal content of PAS-positive material. In stage I this system becomes extremely well-developed and invaginates into the lumen of the ovaries. The PAS-positive content of this system is supposed to originate from the pyloric caeca, which means that in this time mobilization and release of stored reserves from the pyloric caeca can be expected, and as stated above these processes would be favoured by high c-AMP levels in the pyloric caeca, which in this study have been found.

In stage II, in autumn, plenty of food is available and the pyloric caeca are actively synthesizing reserve substances. These processes of biosynthesis are favoured by low c-AMP levels, which in this study have been found. Moreover, it has been observed (Broertjes et al., 1980) that in well-fed animals newly digested materials are released directly, i.e. without intermediate storage, thus bypassing the storage cells. This would imply that, at that time, no high c-AMP levels are needed for mobilization, which is in agreement with the present findings too. After the autumn the feeding activity of the animals decreasesprobably due to lower water temperatures--while the demand for vitellogenesis increases, this will result in an increasing rate of mobilization of reserves in the pyloric caeca, which will be greatly enhanced by increasing c-AMP levels.

In conclusion, this study has shown that the changes in the c-AMP levels in the pyloric caeca of female sea stars are closely paralleled to the stages of the reproductive cycle, and are in full agreement with what could be expected on the ground of the physiological processes going on in the pyloric caeca.

Acknowledgements - The authors are indebted to Prof. Dr G. J. Leppink and Dr Ir. A. J. Faber for their help in statistical analysis; and to Miss Angela de Lange for typewriting the manuscript

\section{REFERENCES}

Anderson J. M. (1953) Structure and function in the pyloric caeca of Asterias forbesi. Biol. Bull. mar. biol. lab., Woods Hole 105, 47-61.

Boolootian R. A. (1966) Reproductive physiology. In Physiology of Echinodermata (Edited by Boolootian R. A.), pp. 561-613. Interscience Publ., New York

Broertjes J. J. S., Posthuma G., Den Breejen P. and Voogt P. A. (1980) Evidence for an alternative transport route for the use of vitellogenesis in the sea star Asterias rubens (L.). J. mar. biol. Ass. U.K. 60, 157-162.

Diehl W. J. (1983) Levels of cyclic AMP in the pyloric caeca, tube feet and gonads of Luidia clathrata (Say) (Echinodermata: Asteroidea). Comp. Biochem. Physiol. 74B, 753-754.

Gilman A. G. (1972) Protein binding assays for cyclic nucleotides. Adv. Cyclic Nuc. Res. 2, 9-24.

Hancock D. A. (1955) The feeding behaviour of starfish on Essex oyster beds. J. mar. biol. Ass. U.K. 34, 313-331.

Harrold C. and Pearse. J. S. (1980) Allocation of pyloric caeca reserves in fed and starved sea stars, Pisaster. giganteus (Stimpson): somatic maintenance comes before reproduction. J. exp. mar. Biol. Ecol. 48, 169-183.

Jangoux M. and Van Impe E. (1977) The annual pyloric cycle of Asterias rubens L. (Echinodermata: Asteroidea). J. exp. mar. Biol. Ecol. 30, 165-184.

Lowe E. F. (1978) Relationships between biochemical and caloric composition and reproductive cycle in Asterias vulgaris (Echinodermata: Asteroidea) from the Gulf of Main. Ph.D. Thesis, University of Maine, Bangor, U.S.A.

Meisner H. and Carter J. R., Jr (1977) Regulation of lipolysis in adipose tissue. Horizons Biochem. Biophys. 4, 91-129.

Miller R. G., Jr (1980) Simulaneons Statistical Inference. McGraw-Hill, New York

Oudejans R. C. H. M.. Van der Sluis I. and Van der Plas A. J. (1979) Changes in the biochemical composition of the pyloric caeca of female sea stars, Asterias rubens. during their annual reproductive cycle. Mar. Biol. 53, 231-238.

Oudejans R. C. H. M., Van der Sluis I. and Voogt P. A. (1983) Triacylglycerol lipase activity in the storage organs of the sea star, Asterias rubens. Comp. Biochem. Physiol. 74B, 587-592.

Schoenmakers H. J. N., Goedhart M. J. and Voogt P. A. (1983) Biometrical and histological aspects of the reproductive cycle of the ovaries of Asterias rubens (Echinodermata). Biol. Bull. mar, biol. Lah., Woods Hole 166, 328-348.

Van der Plas A. J. and Voogt P. A. (1982) The biochemical composition of the pyloric caeca and its relation to DNA levels in the female starfish Asterias rubens during the reproductive cycle. J. comp. Physiol. 148, 49-55. 